\title{
VUELTA DE PASEO de Federico García Lorca
}

\section{Myma Solotorevsky}

Este trabaịo se propone ofrecer una "interpretación" de "Vueita de Paseo', poema inaugural de Poela en Nueva York, de Federico García Lorca.

Entendemos "interpretación", según lo hace Tzvetan Todorov en Poétique ${ }^{1}$ como una actividad que tiende a captar uno o alguros de los sentidos posib'es de un texto: sus 'hechos de significación $\sin$ que sea dable eliminar en ella el influjo de la subjetividad².

Nuestro círculo inteiprefativo empleará, para configurar-se, determinados conceptos metalingüísticos, pertenecientes a dos ámbitos, que no estimamos irreconciliables sino complementarios: a) a. una aproximación estructuralis:a, b) a un acercamiento "existencial" a la obra poética. La captación de la estructura del poema nos parece necesaria para llegar a conocer su significación; esta captación se da, a nuestro juicio, - aunque sea de manera inconsciente - en todo buen acio de lectura.

Estimamos que la dimensión del sentido está dada objetivamente en el texto, pero, como señala Ricoeur, "con una objetividad que sólo aparece para la conciencia que la aprehenda". ${ }^{3}$

1 TODOROV, Tzvetan. Pobtique, en Qu'est-ce que le structuralisme, Editions du Sauil, Paris, 1968.

2 "Les faits de signification, qui constituent l'objet de l'interprétation, ne se prêtent pas la "description", si l'on veut attribuer a ce mot le sens d'absolu ef d'objec. tivité". TODOROV. Pobtique. Ob. Cic., p. 17.

Es importante, para una efectiva caplación de este planteamiento, agregar la siguiente afirmación de Todorov: "Mais dire: 'tout est interprétation' ne signific pas: toutes les interprétations se valent". TODOROV. Pobtique. Ob. Cit., p. 17.

3 RICOeUR, PACl, Verstraeten. Claude Lóvi - Strauss. Probiemas dol estructurolismo, Editorial Universitaria de Córdoba, Argentina, 1967, p. 173. 
El análisis que realizaremos atenderá a los dos ejes: vertica! c paradigmático y horizontal o sintagmático. Pensamos que la consideración de estos dos planos, como interdependientes, es necesaria. para la captación de la obra como talt. A modo de un intermedio entre el estudio de ambos ejes, nos ocuparemos de las relaciones metonímicas (plano de contigüidad) y metafóricas (plano de la equivalencia), fal como ellas se dan en el poemá.

Conside:aremos el poema según lo presenta Editorial Losada 5 . Curiosamente, la variación de un sólo término, crea un poema absolutamente distinto en la versión que de él ofrece Aguilar. Oportunamenie daremos cuenta de este hecho.

\section{VUELTA DE PASEO}

I 1 ASESINATO por el cielo,

2 en:re las formas que van hacia la sierpe

3 y las formas que buscan el cristal,

4 dejaré crecer mis cabellos.

11 Con el árbol de muñones que no canta

2 y el niño con el blanco rostro de huevo.

III I Con los animalitos de cabeza rota

2 y el agua harapienta de los pies secos.

IV 1 Con todo lo que tiene cansancio sordomudo

2 y mariposa ahogada en el tintero.

$\checkmark$ I Tropezando con mi rostro distinio de cada día

4 Samue: Levin remite claramente a esia distineión entre ambos ejes en linguistic structures in Poetry: "Lingustic analysis distinguishes two planes of language - the syntagmatic and the paradigmatic - and, although it is customary, in American linguistics, to treat the syntagmaitc plane as semehsw the more important of the two inasmuch as presumably it exists as such and is therefore open to inspection it would be a mistake to beieve that it is any more amenabie to analysis. The fart is, of cour:e, that there is a real inferdependence between these two planes of language when we consider each plane from the point of view of the other, paradigms are found is consist of members of syntagms and syntagms to cansist of paradigms." LEVIN, Samue:. Linguistic Slructures in Poetry, Monton and Co. The Haghe, 1962, p. 19.

5 GARCÍA LORCA, Federico. Poeta on Nuava York. Conferencies. Prosas póstumas, Editorial Losada, Buenes Aires, segunda ediëón. 1944.

6 GARCÍA LORCA, Fedzrico. Obras Completes, Aguilar, Madrid, tercera edición, 1957. 


\section{Eje Paradigmático}

\section{A. - Metalenguaje Estructural}

\section{I. - Descripción de algunos rasgos mé!ricos.}

Nos encontramos frente a un poema constituído por un tí ule $y$ cinco estrofas.

La estrofa piimera duplica en cuanto al número de ve sos a las otras cuatro, destacándose materialmenie en el poema.

Riman con rima asonante (e-o) el tífulo y los versos $1,1,1,4$, $11,2,111,2, I V, 2$ y $V, 2$.

La rima asonante configura a la primeira estiofa como un ám bito cerrado; los veisos que lo enmarcan son isosilábicos (octosilábicos). El resto del poema aparecería en es'e nivel como una expansión y eco de la primera estrofa.

La rima crea un efecto de monotonía encantatoria, que anuncia ya la dificultad de una rupiura.

\section{1. - Configuración del poema a base de "couplings".}

Levin estima el "conpling" com una de las estructuras impor. tanies en poesía; dicha estructura ocurre cuando se da la convergencia de dos tipos de equivalencia: equivalencia posicional: Tipo 1 y equivalencia natural (fónica $y / 0$ semántica): Tipo Il. Levin señala dos clases de equiva'encia posicional: la sintajmática y la convencional; para los efectos de nuestro análises consideraremos sólo la primera.

Tal como reconoce Levin, el "coup'ing" resul'a pe'fectamente comprensible a partir de la ley de Jakobson: "The postic function projects the principle of equivalence from the axis of selection into the axis of combination. Equivalence is promoted to the constitutive device of the secuence ${ }^{\prime \prime}$.

El "coupling" se advierte ostensiblemente como una estructura básica en la configuración de nuest:o poema. Distinguimos en él

7 JAKOBSON, Roman. "Linguistic and Poetics", en Style in Languago, edited by Sebeok. The M.I.T. Press, 1971, p. 358. 
tres "couplings", que denominaremos $C_{1}, C_{2}$ y $C_{3}$.
$\mathrm{C}_{1}$ incluye $\mathrm{I}, 1$ y $\mathrm{V}, 2$
$\mathrm{C}_{2}$ incluye 1,2 y 3
$\mathrm{C}_{3}$ incluye $\mathrm{II}, \mathrm{III}$ y IV

Presentaremos dos esquemas: uno en el que los "couplings" serán señalados en el poema - para no perder así la visión total de éste - y otro, en que, para mayor claridad, los "coupling" serán abstraídos del poema.

\section{VUELTA DE PASEO}

ASESINADO por el cielo, entre las formas que van hacia la sierpe

y las formas que buscan el cristal, dejaré crecer mis cabellos.

Con el árbol de muñones que no canta $y$ el niño con e! blanco rostro de huevo.

Con los animalitos de cabeza rota y el agua harapienta de los pies secos.

Con todo lo que trene cansancio sordomudo y mariposa ahogada en el tintero.

Tropezando con mí rostro distinto de cada día. IAsesinado por el cielo!

\section{$\begin{array}{llll}1 & 2 & 3 & 4\end{array}$}

$C_{1}$ ASESINADO / por / el / cielo / asesinado / por / el / cielo / $\begin{array}{lllllll}1 & 2 & 3 & 4 & 5 & 6 & 7\end{array}$

$\mathrm{C}_{2}$ entre / las / formas / que / van hacia / la / sierpe / $y /($ entre)* / las / farmas / que / buscan / el / cristal / $\mathrm{C}_{3}$ Con / el árbol de muñones que no cania // y/ el niño con el blanco rostro de huevol

Con / los animalitos de cabeza rota // y/ el agua harapienta de los pies secos/

Con / todo lo que tiene cansancio // y/ mariposa ahogada en sordomudo el tintero/

\section{Equivalencia natural}

* El término colocado entre paréntesis corresponde a la actualización de un término "sub-entendido".(11; 
$C_{1}$ : la relación que se da entre sus miembros es de iaientidad semántica y fónica ${ }^{8}$.

Los miembros constifutivos de $C_{1}$ confieren al poema una estructura cerrada 9 .

$C_{2}$ : la identidad semántica y fónica de sus miembros se transforma a partir de la unidad 5 en formas más libres de equivalencia semánłica: similitud (dinamicidad de "van" y "buscar"); antítesis 0 similitud (entre "sierpe" y "cristal", intensificada como efecto de la idientidad $y$ de la similitud anteriores) ${ }^{10}$

$\mathrm{C}_{3}$ : los tres miembros son idénticos semántica y fónicamente en la primera unidad; semánticamente similares, en la segunda (entes degradados); idénticos semántica y fónicamente, en la tercera unicad; semánticamente similares en la cuarta (entes degradados). Si comparamos los términos que siguen a la preposición "con" en cada esirofa: "el" (II,I), "los" (II,I), "todo" (IV,I), advertiremos una progresión que va de lo singular a lo plural y a lo indefinido - genérico, la cual enfariza la universidad de la situación configurada. La misma progresión hacia. lo genérico se advierte al comparar: "el niño" (II,2), "el agua" (III, 2) y "mariposa" (IV,2). ${ }^{12}$

\section{Equivalencia posicional. ${ }^{13}$}

Los miembros de cada "coupling" son posicionalmente compa-

a Levin scriala ia diferencia entre equivalencia e identidad: "Equivalence is of course not the same as ident.ty; identity is the narrower relation." LEVIN, Ob. Cit., p. 22. Nosotros estimaremos "equivalencia" como un género en el que se incluyen: similitud, identidad, artitesis.

- Si cancebimos que toda obra, por ser autónoma, posee una estructura cerrada, se trataría en casos como éste, de una clausura en segundo grado, clausura cuyo énfasis cobra importancia en la configuración de mundo.

10 Este punto será cansiderado a: realizar el análisis sintagmático del poemo.

11 Levin dice al respecto: "The use of zeros makes the analysis simpler, it is not cssential." LEVIN, Ob. Cit., p. 53.

12 Ruwel destaca la necesidad de no separar el estudio de los factores de simetría en especiol los "couplings", de estudio de los factores de asimetría, que equilibrarian a los primeres. RUWET, Nicolas. "L'analyse structurale de la poésie", en: Langage, musiquo, poésie. Editions du Seuil, Paris, 1972.

13 Levin indica dos ciases de posiciones equivalentes: posiciones comparables $y$ posiciones paralelas: "In a construction like ACAN, the two $A$, as both modifying the same head. are positions which are comparable. Thus, in "tall but wooden buidings, tell and wosden occur in comperable positions." "Another way in which positions may be equivaient is where they are parallel in thcir construct:ons; for example the cons. truction ANCAN, as in "good food and soft music", both as modifiers, but of different heads." LEVIN. Ob. Cit. p. 33. 
rables, en cuanto a que cumplen una misma función determinante respecto a un determinado común (tienen la misma relación con respecto a la proposición principal: "dejaré crecer mis cabellos"). Por otra parte, en el interior de dichos miembros, las unidades están en posiciones paralelas.

Luego del intento descriptivo, nos parece esencial el preguntarnos sobre la función que los "couplings" cumplen en el poema. Esta interrogante quedará pendiente has'a una etapa uiterior del análisis.

Observemos, por el momento, que no constituyen "coupling" en el poema, el título, el verso cuarto de la estrofa segunda y el verso primero de la estrofa quinta.

El tífulo podría ser separado del cuerpo del poema; 11,4 y $V, i$ son, por su parte, los únicos versos del poema en los que se manifiesta una actividad del hablante.

\section{III. - Paradigma. ${ }^{14}$}

Como consecuencia de la citada ley de Jakobson, se entiende que en el eje sintagmático del poema, se combinen elementos los cuales, sobre la base de su equivalencia na:ural, constituyen clases de equivalencias o paradigmas. ${ }^{15}$

Distinguiremos en el poema dos clases de paradigmas: semánticos y funcionales. Al lado de cada término o expiesión, señalarema. ${ }^{18}$

Paradigmas semánticos.

\section{1) Términos que remiten al ámbito de la naturaleza}

14 Barthes destaca la importancia de la noción "paradigma" pora ei estructuralismo, en su ensayo "La actividad estructuralista". BARTHES, Roland. "La actividad estructuralista" en: Ersayos Crítices, Seix Barral. Barcelona, 1973.

15 En "E.ementos de Semio'ogia". Barthes se refiere a la trarsgresión de la división copriente sintagma - sistema y señala: "es probiblemente alrededor de esta ironsgresión donde se encuentra un e'evado número de fenómenos creativos", BARTHES, Roland. "Elementos de Semiología", en la Semioiogia, Editorial Tiempo Contemporáneo, Argentina, 1972.

I6 Por cierto que según cual sea el criterio clasificatorio que opera en cada caso, un término podrá pertenecer a diferentes paradișmes; como entendemos que la identidad es una forma de equivalencia habrá la posibilidad de paradigmas constituidos por un solo término. 
ciclo $(1,1 ; V, 2)$

árbol $(I 1,1)$

animalitos (III, I)

agua (III, 2)

mariposa (IV,2)

huevo $(I 1,2)$

sierpe $(1,2)$

2) Términos que remiten al ámbito corpóreo.

Cabellos $(1,4)$

muñones (II, 1)

rosiro $(I 1,2 ; V, 1)$

cabeza (III, 1)

pies (III,2)

3) Términos denotadores de daño.

Asesinado $(1,1 ; V, 2)$

muñones $(I I, 1)$

rota (III, l)

ahogada (IV,2)

tropezando $(V, 1)$

4) Tórminos connotadores de vitalidad.

crecer $(1,4)$

cabellos $(1,4)$

5) Expresiones disfóricas.

no canta. (II, I)

blanco rostro de huevo (II,2)

animalitos de cabeza rota (III,1)

água harapienta de los pies seros $(I I I, 2)$

cansancio sordomudo (IV, I)

mariposa ahogada en el tintero $(\mathrm{IV}, 2)$

Tropezando con mi rostro distinto de cada día $(V, 1)$

Paradigmas funcionales.

1) Preposiciones.

de (tifulo; II, 1; III, 1; III,2; V, I)

por $(1,1 ; V, 2)$ 
entre (1,2)

hacia $(1,2)$

con $(I 1,1 ; 11,2 ; 111,1 ; I V, 1 ; V, 1)$

2) Conjunciones.

y $(1,3 ; 11,2 ; 111,2 ;$ IV,2)

\section{Observaciones.}

El paradigma semántico 1 está constituído por cuatro términos que en el poema resultan degradados y uno (muñones) que normalmente connota deficiencia.

El paradigma semánitico 2 está constituido por tres términos "degradados" (rostro, cabeza, pies) y uno que, por oposición, aparece como vital (cabellos).

Los paradigmas semánticos 3 y 4 están en relación de oposición.

El paradigma funciona! 1 (la abundancia de preposiciones) sugiere la existencia, en el mundo diseñado, de relaciones cuidadosamente especificadas.

El paradigma funciorial 2 (reiteración de la conjunción " $y$ ") permite que mediante el enlace, se intensifique el efecto de acumulacrón propio del poema.

\section{IV. - Isotopías sománticas. ${ }^{17}$}

En un primer plano, captamos dos isotopias semánticas, en relación antitéticas:

$I_{1}$ : degradación, aniquilamienio.

$I_{2}$ : enf:entamiento, rebelión.

Desde el punto de vista temporal, $l_{1}$ corresponde a la circunstancia actual $e l_{2}$ es una resolución o un proyecto $y$ apunta, por lo tunto, hacia el futuro.

I. prima cuantitativamente sobre $I_{2}$. El poema se configura mediante una progresiva expansión de $l_{1}$ interrumpida por un so'o

17 Eniendemos "isolopí semántica", como plano de significación homogénea. Véase ol respecto: GREiMAS, A. G. Semántica Estructural, Gredos, Madri, 1973. ("La isotopía del discurso". PP. 103 - 155). 
verso, a! final de la primera estrofa $(1,4)$; dicho verso se destaca por su singularidad semántica (el único verso correspondiente a $l_{1}$ ) $Y$ sintáctica (la única frase subordinante del poema).

En ofro plano, surge como posible una nueva distinción de zonas isótopas:

$l_{1}$ : ámbito concerniente al "yo".

$I_{2}$ : ámbito concerniente a "lo otro", que afecta al "yo".

$I_{1}$ : incluye: ASESINADO $(1,1)$

dejaré crecer mis cabellos $(1,4)$

tropezando con mi rostro distinto de cada día $(V, 1)$ Asesinado $(\mathrm{V}, 2)$

Los elementos pertenecientes a $I_{2}$ pueden ser clasificados del siguiente modo:

a) agente que asesina: cielo $(1,3)$

b) entes entre los que el hablante está: formas que se orientan hacia dos polos opuestos (la sierpe y el cristal) $(1,2$ y 3)

c) entes con los que el hablante está. (II, III, IV)

$l_{2}$ predomina cuantitativamente respecto de $l_{1}$ manifestando la potencia de un cosmos adverso y aniquilador.

$I_{1}$ se plasma en la primera y en la última estrofa del poema, configurándose así un círculo, intensificado por la reiteración del primer verso al final del poema $\left(C_{1}\right)$.

\section{Observaciones.}

La capłación de isotopias semánticas nos permite la unificación de algunos rasgos advertidos en momentos anteriores del anblisis y la adjudicación a ellos de un sentido.

Las isotopías semánticas muestran claramente un enfrentamiento entre "lo otro" (aniquilamiento) y el "yo" (rebelión), y un predominio cuantitativo de fue:zas adversas al "yo". Podemos ahora captar que diferentes elementos ya destacados, coadyuvan a ello: el efecto de monotonfa encantatoria suscitado por la rima, la configuración repetitiva y unificadora correspondiente a los "couplings"18; el

18 Respecto de la función de los "couplings", Levin señala: "It is in this way that coupling serves to unify a poem. Not only is the vocabulary of a poem very res. tricted, in this special sense; it is also very uniform. This same structural fact is what makes a poem memorable." LEVIN. O'b. Cit. p. 39. 
hecho de que no constituyen "coupling" es decir, carezcan de consistencia y hamogeneidad, los versos en los que se manifiesta una actividad del hablan'e lírico; el predominio de términos degradados $y$ disfóricos en la composición de los paradigmas semánticos; la cuidadosa especificación de relaciones sugerida por el paradigma funcional, que permite mostrar la eficácia e ineludibilidad del aniquilamiento; el efecto acumulativo logrado por el paradigma funcional 2, que refieja la acumulación de lo adverso.

\section{V. - Actitud lírica predominante.}

Kayser distingue en Interpretación y análisis de la obra literaria ${ }^{19}$ tres actitudes líricas funciamentales:

enunciación lírica: "el yo está frente a un 'ello', frente a un 'ente', lo capta y lo expresa."

apóstrofe lírico: "aqui no permanecen separadas y frente a frente las esferas animica y objetiva, sino que actúan una sobre otra, se desarrollan en el encuentro, y la obje:ividad se iransforma en un 'tú'."

lenguaje de la canción: "aqui ya no hay ninguna objetividad frente al yo y actuando sobre él; aquí ambos se funden por completo; aquí es todo inte-ioridad. La manifestación lírica es la simple autoexpresión del estado de ánimo de la interioridad anímica."

En cada poema una de estas tres actitudes - piensa Kayser adjudicará el predominio estructural, configurando al poema como unidad.

En "Vuelta de Paseo" captamos como actitud lírica predominante, el lenguaie de la canción: el poema se muestra como auioexpresión de la interioridad anímica del hablante lírico. Sin embargo, en modo alguno admitiriamos que ya no hay ninguna objelividad frente al yo. Diriamos que la objetividad del mundo es fielmente captada a través de la intericridad del hablante; ésto la impregna de su subjetividad y la hace visible.

\section{B. - Metalenguaje existencial}

1. - Temple de ánimo.

19 KAYSER, Wo'fgang. inferprotación y análisis de al obra itteraria. Gredos, Madrid, 1954. P.. $541-560$. 
Podría llamar la atención el que no nos contentásemos en el metalenguaje estructural hasta aquí empleado y súbitamente requiriésemos un concepto mucho más vago e impreciso, cual es "temple de ánimo".

Ocurre que pensemos que sin la captación del temple que enima a un poema, no se da la desocultación del objeto estético en cuanto a revelador de la verdad. ${ }^{20}$

Los differentes niveles estructurales señalados, y sus relaciones, permiten el surgimiento de un temple determinado que variará só!o hasta cierto límite, en distintos actos de lectura.

Capiamos el temple de ánimo básico del poema, como un temple de profunda tristeza y de dolorosa asuncion.

Dicho temple entrará en un juego tensional con el "sentido" último del poema en virtud del cual éste logrará su plena patentización.

\section{II. - Sentido último del poema, captable en muestro círculo do lectura.}

La descripción de los diferentes niveles configurados, culmina a nuestro juicio, en la captación de este "sentido último", hacia el que se proyecta el poema como unidad.(21)

El "sentido último" que nos ha entregado el texto, es la patentización de una "rebelión absurda", expresión que empleamos

20 Señala a este respecto Pfeiffer, en su texto La poesía: "Heidegger habla de la fuerza reveladora del temple de ánimo; Jaspers, de su virtud iluminadora. En nuestro estar tempiados, atemperados, y por medio de él, se pone de manifesto lo que ocurre en lo más profundo de nuestro ser: el temple de ánimo nos coloca ante nosotros mismos traiciona algo de las secretas profundidades de nuestra verdadera situación." PFEIffer, Johannes, La poesía, Fondo de Cuitura Económica, México, 1954, p. 54 .

21 Respecto del problema dei "sentido", concordamos con lo posición de Ricoeur: "Je voudrais ou contraire montrer que ce qui arrive dons l'ácriture, c'est lo pleine manifestation de ce qui est à l'état virtuel, naissant et inchoatif dans la parole vive, à savoir ie défachement du sens a l'égard de l'évenement." Ricoeur, Poul. "Evénement et sant dins le discours." en PHILIBERT, Michel. Ricoeur, Seghers, Paris, 1971, p. 179.

"Le sens d'un texte n'est pas derribre lui, du cBite de l'intention présumée de son auteur, mais en avant de lui, du côté de sas références non - ostensives, du cóté du monde qu'il ouvre." Ricoeur, Paul. "Evénement et sens dans le discours". en Phi.ibert. Michel. Ob. C.t., p. 185. 
según el uso que de ella ofrece Albert Camus. ${ }^{22}$

El temple básico de asunción respecto al predominio de la circunstancia adversa y no obstante - la insistencia en la rebelión, es y onfatizan la heroica absurdidad de esta última $y$ corresponden a la esencia misma del poema que estudiamos.

\section{Relaciones metonímicas y metafóricas}

Jakobson señala como corolario de su ley: "In poetry where similarity is slightly metaphorical and any metaphor has a metonymical tint." ${ }^{\text {"23 }}$

Nuestro poema es:á configurado por una red consistente de imágenes metonímicas, algunas de las cuales logran una especial proyección metafórica. Dichas relaciones metonímicas son:

1) La vinculación entre el cielo y el "yo"; estos términos se encuentran en relación de: agente - paciente.

El cielo - en relación metonímica con Dios - asume una evidente proyección me:afórica, encarnando lo todopoderoso, lo sacro, que ejerce una acción destructora sobre el hablante.

2) La vinculación entre el "yo" y los otros entes y de éstos entre sli dichos entes son:

a) las formas que van hacia la sierpe

b) las formas que buscan el cristal

c) el árbol de muñones que no canta

d) el niño con el blanco rostro de huevo

e) los animalitos de cabeza rota

f) el agua harapienta de los pies secos

g) todo lo que tiene cansancio sordomudo y mariposa ahogada en tintero

h) mi rostro distinto de cada día

22 "Constifuye un honor metafísico defender la absurdidad del mundo. La con. quista o el juego, el omor innumerable, la rebelión absurda son homenajes que e! hombre tributa a su dignidad en una campaña en que está vencido de antemano." CAMUS, Albert. "El mito de Sisifo", en: El miro de Sisifo. El hombre rabelde. Losada, Buenos Aires, 1953, p. 76.

23 JAKOBSON, Roman. Ob. Cit., p. 370. 
En c), d), e), f), h), se da además, una relación sinecdóquica entre dos términos, respectivamente: muñones - árbol, blanco rostro de huevo - niño, cabeza rota - animalitos, pies secos - agua (aqui coexiste con la relación sinecdóquica, una relación de antonimia), rostro - yo. En cada caso, la "parte" corresponde al ámbito corpóreo.

En h), el rostro del hablante adquiere una relevante proyección metafórica: pasa a representar su propia identidad alienada o enajenada.

Todos estos ontes en relación metonímica con el hablante, pasan a encarnar metaforicamente, una circunstancia existencial degradada, de la que el hablante es partícipe y víctima.

\section{Eje Sintagmático}

\section{mática. \\ I. - División del poema desde el punto de vista de la sintag-}

El poema nos parece deslindable en cuanto a unidades, no siendo esta división redundante respecto de una realizab!e desde el punto de vista métrico.

I: corresponde al título.

II: corresponde a la primera estrofa.

III: corresponde a las estrofas 2, 3 y 4.

IV: corresponde a la estrofa 5.

La señalada falta de correspondencia entre división sintagmática y métrica, ocurre exclusivamente en la unidad III y podemos señalar cuál es la función que ese rasgo cumple en el poema.

La unidad (III) configura un "coupling" $\left(C_{3}\right)$ perteneciente a $l_{1}$, es decir, una zona unificada en la que imperan elementos adversos al "yo". Los espacios en blanco luego de las estrofas II y III - al interrumpir el desarrollo del discurso - permitiría suponer la cesación del aniquilamiento; al ser éste luego reanudado, resulta intensificado, apareciendo debilitadas las posibilidades del "yo".

\section{II. - Organización sintácilica del poema.}


Como ya hemos antecipado, el poema consta de una frase sutordinante (el verso l, 4), respecto del cual el resto de la composición, constituye un conjunto de frases subordinadas.

Esta peculiar organización sintáctica hace más tenso el conflicto entre "lo otro" (cuantitativamente predominante) y el yo, y apunta a ta "rebelión absurda" del hablanie.

\section{III. - Análisis sinfagmático.}

El acto de lectura obedece estrictamente al orden sintagmático del poema, y éste no puede ser descuidado en el análisis. Solamente en virtud de la adhesión a la progresión sintagmática, podremos captar cómo se realizan los niveles hasta ahora abstractamente aprehendidos, en la concreción del poema ${ }^{24}$.

Señalaremos en cada caso el número de la unidad correspondiente (aivisión del poema desde el punto de vista de la sintagmática) y el número de la est:ofa y verso ce que se trata.

Cuando nos parezca de interés - sin adjudicar a ello categoría de necesidad - citaremos versos correspondientes a otros textos lorquianos, relacionables con nuestra poesía; ello se funda en la consideración de la obia de García Lorca, como una estructura mayor, respecto de la cual este poema, sería una subestructura.

Daremos importancia a las repercusiones simbólicas que sugiere cada imagen, asumiendo la visión de la poesía como actividad desocultante, capaz de revelar estructuras arquetípicas.".5

(1) Título: Nos sume en un ámbito apaientemente in:rascendenie; el término "paseo" está genericamente señalado (en oposición a: "del paseo", "de un paseo"); el término "vuelta", sinónimo de retorno, prefigura la circularidad del poema.

24 No concordamos con e! concepto de "superreader" que emplea Riffaterre, por Farecernos artificial; pero alabamos el cuidado y la agudeza con que este crítico realiza el análisis sintagmético de un poema. Vésse RIfFATERRE. Michel. Essais de stylistique seructurale. Flammarion. Paris, 1971. Ver: "La description des structures poétiques: daux approches du poéme de Baudela're, "Les Chats".

25 Vésse al rest'scto: JUNG, C. G. "Psychoicgy and titerature", en: the spirit in man. Ant and Liferature, Princeton University Press, 1972. Señala este autor que lo que aparece on la visión (poesía visionaria) son las imógenes del inconsciente colectivo. 
I,I El verso se inicia con un participio pasado, cuyo significado cobra especial fuerza, debido al ampleo de mayúsculas ${ }^{20}$; el aspecto pérfectivo del participio, nos sitúa frente a una acción que ya se ha ejercido sobre el hablante.

El agente de la acción (asesino) es el cielo. Ello aparecería como una captación monofacética de un orden simbólico, el cual reconoce tanto el aspecto benévolo del cielo (éste es concebido como morada de Dios; se le atribuyen: trascendencia, fuerza, sacralidad; se lo vincula a salvación) como su aspecto terrible (lo sagrado como tremendo, asociado a la catástrofe cósmica, al apocalipsis"27. El "cielo" del poema actualiza sólo este segundo aspecto.

Esta imagen de un cielo adverso aparece, también, en otro poema de Garcia Lorca: "Gacela del amor maravilloso" (Diván del Tamarit):

"Cielos y cielos
azotaban las llagas de mi cuerpo".

\section{1,2 y 1,3}

El hablante aparece existencialmente situado entre formas dinámicas, en vías de realización ("van hacia.", "buscan').

Las dos clases de formas perecerían tender hacia polos antitéticos: sierpe (lo intrincado, oscuro, malígno, sinuoso, deslizante) y cristal (lo transparente, geométrico); pero en este contexto, ambos términos podrían también ser estimados como semánticamente semejantes, debido a sus comunes connotaciones disfóricas.

En "Grito hacia Roma" de Poeta en Nueva York, "cristal definitivo" aparece como signo de petrificzción, de ausencia de vida: "no hay amor bajo los oịos de cristal definitivo". Sugestivamente, en este

26 Ei hecho de que en todos los poemas de Poota on Nueva York aparezco el Frimer írmino del cuerpo del poema con mayúscula, no anula la validez de nuestra observación, respecto de este poema singular.

27 Mircea Elisde desarrolia la visión de lo sagrado como tremendo, en Miros, sueños y misterios. ELLADE, Mircea. Mitos sueños y misterios, Compañía General Fabril Editores. Buanos Aires, 1961, p. 235. 
mismo poema se configura, también, la imagem de la sierpe: "e! amor está en los fosos donde luchan las sierpes del hambre".

En "nocturno del hueco", Poeta en Nueva York, se da también la conjunción de ambas imágenes:

"y eran duro cristal definitivo

las formas que buscan el giro de la sierpe."

La base uniforme brindada en "Vuelta de paseo" por el "coupling", intensificaría una a ofra posibilidad: antítesis o similitud.

\section{1,4}

Hemos destacado al referirnos a las isotopías semánticas, la singularidad de este verso. Hemos señalado que se trata de la única frase subordinante del poema. Especifiquemos, ahora, que "dejaré" es el único verso del poema cuyo sujeto es el hablante lírico; es también el único verbo del poema cuyo tiempo es futuro; connota certeza, resolución, inherentes al hablante.

El infinitivo "crecer" connota vitalidad. Los cabellos son una manifestación energética; connotan, también, vitalidad, fertilidad.

Hemos señalado anferiormente que este verso se opone semánticamente al resto del poems.

En (I) se síntetiza la circunstancia existencial del poema.

El ritmo de esta unidad, lento y prolongado, la entonación descendente, sugieren un temple de asunción más que de rebelión o fuerza, ello no obstante la resolución configurada en el último verso de la estrofa y el especial realce del término "cabellos".

(III)

Se díseña el ámbito de los entes que coexisten con el hablante.

La atmósfera plasmada es absolutamente disfórica y adquiere mayor consistencia y homogeneidad debido al "coupling".

II,1 
El árbol aparece aquí como la inversión de un simbolo tradicional: el árbol de la vida (Génesis, 2,9). El árbol suele representar la vida del cosmos, su crecimiento, generación y regeneración. ${ }^{28}$ Por oposición se configura en el poema un árbol mutilado y mortuorio. ${ }^{2 \theta}$

\section{1,2}

El niño representa simbolicamente la fuerza juvenil que despierta.

En el poema, el rostro del niño aparece no formado, desprovisto de rasgcs y expresión. El huevo simboliza lo potencial, sugiere fragilidad. El color blanco en su aspecto negativo es color de muerte. La preposición "con" remite a una relación que nos parece más externa que la señalada por la preposición "de".

\section{III,I}

El término "animalitas" connota afectividad; el diminutivo subraya la precariedad de estos entes destruidos e indefensos.

En "Luna y panorama de los insectos", Poela en Nueva York, aparece la seguiente imagen de los insectos:

"Pido a la divina Madre de Dios,

Reina celeste de todo lo criado, me dé la pura luz de los animalitos

que tienen una sola letra en su vocabulario".

\section{III,2}

Las aguas simbolizan la totalidad de las virtualidades; son matriz de fodas las posibilidades de existencia, la esencia de la vegeta. ción, el elixir de la inmortalidad; confieren larga vida y fuerza creadora. 30

28 CIRLOT, Juan Eduardo, Diccionario do símbolos iradicionales, Luis Miracle, Ediror, Barceiono, 1958, s.v. "Grbol".

oposición se configura en el poema un árbol mutilado y mortuo-

29 En "Paisaje" de Canciones, aparece la siguiente imagen, contrastante con la de nuestro poema:

"Detrás de los cristales

turbios, todos los niños,

ven convertirse en pbjaros

un Grbol amarillo."

30 ELIADE, Mircea. Tratado de Historia de las Religiones, Instituto de Estudos Políticos, Madrid, 1954. V.: "Las aguas y el simbolismo acuático." 
El agua antropomorfizada del poema, aparece degradada en virtud de sus determinativos: el calificativo "harapienta" y el sintagma "de los pies secos". El término "seco" está en relación antitética con agua, originando un oximoron; el término "pies" se vincu'a a tierro, intensificando la contradicción.

En un poema surrealista de Henri Pastoureau, "El grito de la medusa", hemos encontrado la siguiente imagen que asociamos a ésta:

"el agua fría tiene las piernas desnudas

pero no se le ven los muslos"

\section{$\mathbf{N}, \mathbf{I}$}

Se hace una generalización, - o la que ya nos hemos referido al hablar de los "couplings" - reuniendo a todos aquellos entes que t:enen "cansancio sordomudo", el cual captamios como un cansancio integral, que no permi:e ninguna comunicación con el mundo exterior.

Este verso se diseña claramente en dos hemistiquios; el primero fodría reflejar abundancia, plenitud (tiene), expectativa anulada al realizarse el segundo, con sus connotaciones absolutamente adversas.

\section{$\mathbf{N}, 2$}

La mariposa es emblema del alma y de la atracción inconsciente hecía lo luminoso; es símbolo del renacer. En el poema, aparece ahogada en un medio que no le es natural.

En "Fábula y rueda de los tres amigos", Poeta em Nueva York, hay una mención despectiva del tintero:

"Estaban los tres momificados, con las moscas del invierno, con los tinteros que orina el perro y desprecia el vilano",

En "Ciudad sin sueño", Poeta en Nueva York, aparéce una imagen de las mariposas, correspondiente al irrumpir de la vida:

"Otro día

veremos la resurrección de las mariposas disecadas y aun andando por un paisaje de esponjas grises y barcos mudos veremos brillar nuestio anillo y manar rosas de nuestra lengua." 
IV, 1 y IV, 2 crean una ruptura en el "coupling" $\left(C_{3}\right)$, por suprimirse aquí las relaciones sinecdóquicas que encontráramos en 11 y $\mathrm{II}$; "cansancio sordomudo" y "mariposa ahogada en el tintero" son dos cbjetos de "tener"; se produce, así, una intensificación del encaba!gamiento de las dos estrofas anteriores.

\section{$\mathbf{V}, \mathbf{1}$}

Se configura una experiencia de alienación: el rostro aparece separado del propio "yo" disociación ya prefigurada en la imagen: "el niño con el blanco rostro de huevo (II,2); la variabilidad de esto rostro impide la identidad del "yo".

El término "tropezar" significa denotativamente: "dar con los pies en algún estorbo", "chocar con" y también: "hallar casualmente"; todos estes significados intensifican la situación de enajenación. El verso en gerundio, le asigna duratividad.

\section{$\mathbf{V}, 2$}

El últmo ve:so del poema, entre exclamativos, es una potenciación respecto del verso primero y concentra el temple de ánimo de la totalidad del poema. La confrontación de ASESINADO $(1,1)$ y Asesinado $(V, 2)$, sugiere el mayor debilitamiento del hablante en el último verso.

Hemos señalado, es otro momento del análisis, que este verso constituye con el verso primero un "coupling". Conviene ahora recordar la idea de Tynianov respecto del peligro de la noción "simeirla de los hechos composicionales"; según este autor, no puede tratarse de simetría cuando hay una intensificación. Dice Tynianov: "L'unité de l'oeuvre n'est pas une entité symetrique ef close, mais une integrité dynamique ayant son propre déroulement; ses éléments ne sont pas liés par un signe d'égailté et d'addition, mais par un signe dynamique de corrélation et d'intégration. ${ }^{31}$

Concordamos con el pensamiento de Tynianov - que vinculamos a la idea de "virtud pioteica" de Pfeiffer ${ }^{32}$ - y entendemos que el último verso no es "simétrico" respecto del primero: está teñido de todos los elementos que el poema ha ido desplegando sucesivamente;

31 Tynianov, J. "La notion de construccion", em TODOROV. Th6orlo do la Litterature. Du Seuil, Paris.

32 PfEIfFER, Ob. Cit. p. 31. 
el ser mismo del poema, dado en la lectura, suscita esa irreconciliaEle diferencia entre los dos versos límites.

En el acto de relectura, el título del poema perdería su inocencia e intrascendencia, pues el lector virtual sabe ya cuál es la indole -- existencial y funesta - del paseo de que se trata; esta "vuelta" se reconocería como parte de un círculo ineludible. ${ }^{33}$

En virtud de la reiteración de estos dos versos - no simétricos - el poema adquiere una estructura cerrada, y el mundo en él configurado eme:ge como un ámbito sin escapaioria. El afán del hablante por "dejar crecer sus cabellos", encontrándose sumido en la circunstancia descrita, asume el carácter de "rebelión absurda."

Destaquemos, para finalizar, que en edición Aguilar se crea un poema distinto - oiro poema - al substituir el verso 1,4 por: "dejaré caer mis cabe!los". En este nuevo poema, el hablanie lírico, vencido, se entrega a su circunstancia como las otras criaturas descritas, y desaparece todo asomo de conflicto y rebelión.

\section{Condusianes}

Hemos abordado el análisis del poema desde diferentes niveles, y las relaciones que surgen entre ellos, han permitido la captación del foema como unidad.

Hemos mostrado que diversos elementos coadyuvan a la configuración de un orden consistente e inalterable: la rima, los "couplings" la estructura cerrada del poema, su circularidad, los paradigmas funcionales, las relaciones metonímico - metafóricas, la no redundancia de la división sintagmática y métrica.

La distinción de paradigmas semánticos, de isotopias semánticas, la captación de la actitud lírica predominante, del temple de ánimo, de un "sentido último" del poema, que se afirma en su relación tensional con dicho temple, el reconocimiento de las relaciones metonimico - metafóricas, de la división sintáctica del poema, nos han permtido aprehender cuál es la naturaleza de ese orden inaltorable (realidad aniquiladora) y cuál es la reacción del hablante lírico respecto de él (asunción, rebelión absurda).

33 Riffaterre da lo debida impsrtancia al seto de relectura: "When the reading is over, gobal, summative apprehension of the text through rereading and remembering is certainhy part of the literary at of communication. Then, the total of all data and knouwledge of the ending surges back to modify what we porceived at the beginning": RIFFATERRE. Ob. Cit. p. 232. 
El análisis sintagmático nos reveló cómo se realiza el dinamismo del poema, ya paradigmáticamente captado, y sus repercusiones en el lector viriual, durante el acto de lectura. Al atender a la repercusión simbólica de las imágenes, apreciamos el frecuente uso de simbolos, ya sea monofacéticamente empleados (en su aspecto negativo) ya sea invertidos (presentados como disfóricos), participando en la configuración de una realidad adversa.

\section{RESUMO}

O trabalho se propöe oferecer uma interpretação de Vualts de passo poema inaugural de Poeta en Nueva York de Federico Garcia Lorca. A interpretaçōo é feita a partir de conceitos metaiingüisticos comuns a dois âmbitos: aproximação estruturalista a aproximação existencial o conclui que diferentes elementos configuram uma ordem consistente e inaiterável, que distinçāo de paradigmas e isatopias semánticos permitem também apreender qual é a natureza dessa ordem e qual é a reação do falante lírico diante dessa ordem. Também a análise sintagmática revela como se realiza o dinamismo do poems e suas repercussōes com o leitor virtual. 